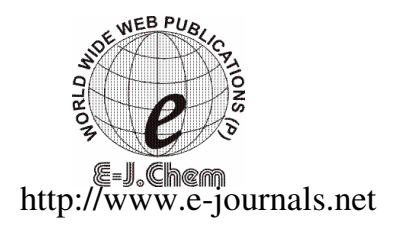

ISSN: 0973-4945; CODEN ECJHAO

E-Journal of Chemistry

2010, 7(S1), S330-S334

\title{
Thermodynamics of Micellization of Nonionic Surfactant Tween-40 in Presence of Additive Chloramine-T Using Clouding Phenomenon
}

\author{
A .A. PATIL ${ }^{*}$ and T. J. PATIL \\ Department of Chemistry \\ JET's Z.B.Patil College, Deopur, Dhule- 424002 (M.S), India \\ ashabhi@rediffmail.com
}

Received 5 February 2010; Accepted 20 April 2010

\begin{abstract}
The phenomenon of solubilization of nonionic surfactant Tween-40 has been studied through the influence of additive chloramine- $T$ in aqueous medium by measuring the cloud points $(\mathrm{CP})$ of the pure surfactant and with chloramine-T. The CP of pure surfactant was found to be increased with increasing concentration of Tween-40. The CP of mixed system shows increasing trends with increased chloramine-T. This is mainly due to increased micelle concentrations. The influence of chloramine-T on the cloud point of Tween-40 is a clear indication that the phenomenon of clouding is associated with the different micelles coalescing. Considering cloud point as threshold temperature of the solubility, the thermodynamic parameters of clouding process $\left(\Delta \mathrm{G}_{\mathrm{cl},}^{0} \Delta \mathrm{H}_{\mathrm{cl}}^{0}\right.$ and $\left.\Delta \mathrm{S}_{\mathrm{cl}}^{0}\right)$ have been evaluated using "Phase Separation Model". The phase separation results from micelle-micelle interaction. It was found that the overall clouding process was exothermic and $\Delta \mathrm{H}_{\mathrm{cl}}^{0}>\mathrm{T} \Delta \mathrm{S}_{\mathrm{cl}}^{0}$ indicating that the process of clouding was guided by both enthalpy and entropy. This work supports the conjecture that the clouding is critical phenomenon rather than the growth of micelles. Findings of the present work supports to made the probable evidence of electrolyte-surfactant interactions in aqueous medium.
\end{abstract}

Keywords: Micellization, Cloud point (CP), Tween-40, Chloramine-T (CAT), Phase separation model

\section{Introduction}

Several research workers have studied the molecular interactions in surfactants in the presence of added electrolytes ${ }^{1-4}$. Surfactants contain two distinct grouping in their structure. Strongly polar or charged group at one end of surfactant molecule is the "head group" which is hydrophilic in nature and long chain of alkyl or aryl group is the "tail" which is hydrophobic 
in nature. When surfactants are added to water at low concentration, they are dispersed as discrete molecules. However, at a particular concentration, surfactant molecules get associated to form aggregates or micelles ${ }^{5-7}$. This concentration is known as critical micellar concentration (CMC) which is an important property of surfactant. Above CMC, the surfactant molecules exist as aggregates or micelles. CMC of a surfactant is determined by several methods such as conductance, surface tension, solubilization, light scattering, diffusion, ultrasonic velocity measurement etc. Nonionic surfactants and electrolytes in aqueous solution cannot withstand at elevated temperatures and become separated which can be seen even with naked eye known as clouding. The cloud point is an important property of non ionic surfactants. Below CP a single phase of molecular solution or micellar solution exists and above $\mathrm{CP}$, the solubility of surfactant in water is reduced and forms cloudy dispersion ${ }^{8}$ by forming giant molecular aggregates in the state of separate phase ${ }^{9-12}$. Polysorbates are a class of emulsifiers used in some pharmaceuticals and food preparations. They are often used in cosmetics to solubilize essential oils in to water based products. Tween-40 is one of the polysorbate. Tween-40 is nonionic detergent used for cell lysis, nuclei isolation and cell fractionation. It is also widely used in cosmetics and some pharmaceutical preparations. Some inorganic and organic compounds are added to detergents in order to make detergent cheap, user friendly and to boost it's power ${ }^{13}$, these compounds are called "builders". Chloramine-T (CAT) is used as disinfectant, algaecide, bactericide, germicide, for parasite control and for drinking water disinfection. Due to these properties CAT is used as a "builder" in detergents

In this paper, the results of present study on the clouding phenomenon of pure TW-40 and in the presence, CAT (Scheme 1) at various concentrations has reported. These studies are important in the field of medicinal preparations, agrochemicals, detergents etc. Considering cloud point as threshold temperature of the solubility, the thermodynamic parameters of clouding process $\left(\Delta \mathrm{G}_{\mathrm{cl}}^{0}, \Delta \mathrm{H}_{\mathrm{cl}}^{0}\right.$ and $\left.\Delta \mathrm{S}_{\mathrm{cl}}^{0}\right)$ have been evaluated using "Phase Separation Model".

\section{Experimental}

The nonionic surfactant Tween-40 (M. Wt. 1283.65) and chloramine-T trihydrate (M.Wt. 281.69) were the products of Sigma-Aldrich, USA and these were used as received. Doubly distilled water with specific conductance $2-4 \mu \mathrm{S} \mathrm{cm}$ at $303.15 \mathrm{~K}$ was used in the preparation of all solutions of different concentrations.

The cloud point (CP) was determined by controlled heating of the sample solutions in thin glass tube immersed in beaker containing water, the sample solution was stirred while being heated. The heating rate of sample was controlled by less than $1{ }^{\circ} \mathrm{C} / \mathrm{min}$. The detailed procedure is in our previous publications ${ }^{14}$. The reproducibility of the measurement was found to be within $\pm 0.2{ }^{\circ} \mathrm{C}$. As the $\mathrm{CP}$ values are not small, the observed values have been rounded off to the nearest degree and presented in the tables.

Clouding species:

Tween-40

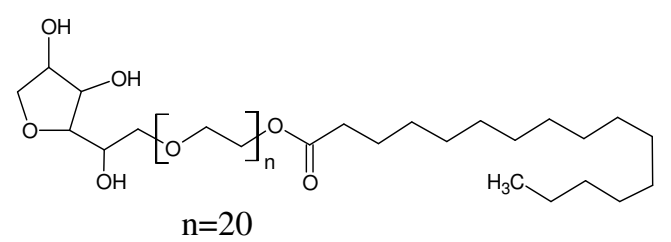

Additive: CAT<smiles>Cc1ccc(S(=O)(=O)N[Na])cc1</smiles>

Scheme 1. Molecular structures of clouding species and additive 


\section{Results and Discussion}

\section{Cloud points of pure Tween-40}

The cloud points of pure surfactant, Tween- 40 at various concentrations in $\mathrm{Wt} \%$ are given in Table 1. The CP of the surfactant Tween-40 was found to be increased with increasing concentration of Tween-40. Above certain concentration of surfactant in aqueous medium, increase in CP was observed which is mainly due to dehydration of oxy-ethylene (EO) group which required still high temperature to remove associated water resulting in to phase separation that is clouding.

Table 1. Cloud points of pure Tween-40

\begin{tabular}{cccc}
\hline $\mathrm{Wt} \%$ & Molarity $\times 10^{-3}$ & Mole fraction $\times 10^{-4}$ & $\mathrm{CP} /{ }^{0} \mathrm{C}$ \\
\hline 2.0 & 15.581 & 2.804 & 94.9 \\
4.0 & 31.161 & 5.606 & 95.7 \\
6.0 & 46.742 & 8.406 & 96.4 \\
8.0 & 62.322 & 11.205 & 96.7 \\
10.0 & 77.903 & 14.003 & 97.2 \\
\hline
\end{tabular}

Table 2. Thermodynamic parameters of Tween-40

\begin{tabular}{cccc}
\hline [Tween-40] Wt \% & $\Delta \mathrm{G}_{\mathrm{cl}} \mathrm{kJ} \mathrm{mol}^{-1}$ & $-\Delta \mathrm{H}_{\mathrm{cl}} \mathrm{kJ} \mathrm{mol}^{-1}$ & $-\Delta \mathrm{S}_{\mathrm{cl}} \mathrm{J} \mathrm{mol}^{-1} \mathrm{~K}^{-1}$ \\
\hline 2.0 & 25.02 & & 1007.8 \\
4.0 & 22.95 & & 1000.0 \\
6.0 & 21.75 & 345.76 & 994.9 \\
8.0 & 20.88 & & 991.7 \\
10.0 & 20.23 & & 988.6 \\
\hline
\end{tabular}

\section{Tween-40/ CAT systems}

The influence of CAT on the CP of Tween-40 at different concentration of CAT has been given as in Table 3. These results indicate that the cloud point of surfactant increased considerably with increased [CAT]. This is due to breakdown of structured additivesurfactant system. The removal of water from surfactant by added electrolyte helps the surfactant micelles to come closer with each other resulting in to increasing of CP.

Table 3. Influence of CAT on CP of Tween-40

\begin{tabular}{cccccc}
\hline [Tween-40] & \multicolumn{5}{c}{ Wt \% of CAT } \\
\hline Wt\% & 0.04 & 0.06 & 0.08 & 0.1 & 0.2 \\
\hline 2.0 & 95.3 & 95.5 & 95.8 & 96.1 & 96.3 \\
4.0 & 95.8 & 96.0 & 96.2 & 96.5 & 97.2 \\
6.0 & 96.5 & 96.6 & 96.8 & 96.9 & 98.2 \\
8.0 & 96.8 & 97.0 & 97.2 & 97.3 & 98.5 \\
10.0 & 97.4 & 97.3 & 97.5 & 97.7 & 98.9 \\
\hline
\end{tabular}

Table 4. Thermodynamic parameters of Tween-40/CAT System

\begin{tabular}{cccc}
\hline$[\mathrm{CAT}] \mathrm{Wt} \%$ & $\Delta \mathrm{G}_{\mathrm{cl}} \mathrm{kJ} \mathrm{mol}^{-1}$ & $-\Delta \mathrm{H}_{\mathrm{cl}} \mathrm{kJ} \mathrm{mol}^{-1}$ & $-\Delta \mathrm{S}_{\mathrm{cl}} \mathrm{J} \mathrm{mol}^{-1} \mathrm{~K}^{-1}$ \\
\hline 0.04 & 32.38 & 369.3 & 1090.6 \\
0.06 & 31.18 & 421.7 & 1228.0 \\
0.08 & 30.36 & 438.7 & 1269.3 \\
0.1 & 29.69 & 482.9 & 1386.1 \\
0.2 & 27.61 & 295.9 & 873.5 \\
\hline
\end{tabular}


The additive surfactant complex is stronger due to solute solvent interaction. Some of the water molecules remain attached to this complex and hence higher temperature is required to breakdown this strong complex system. The dependence of $\mathrm{CP}$ on [CAT] is as depicted in Figure 2

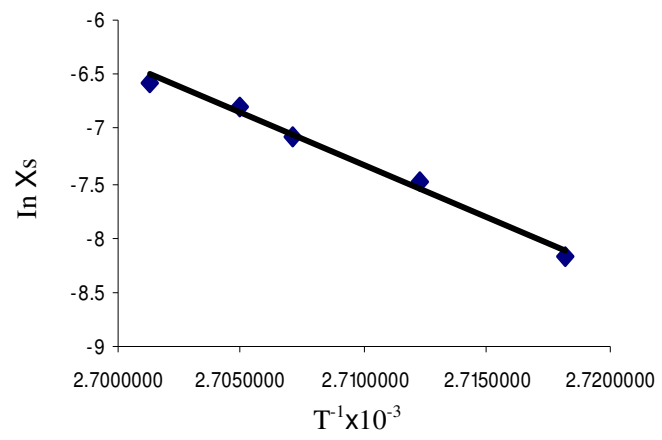

Figure 1. CP of Tween-40 at different concentration

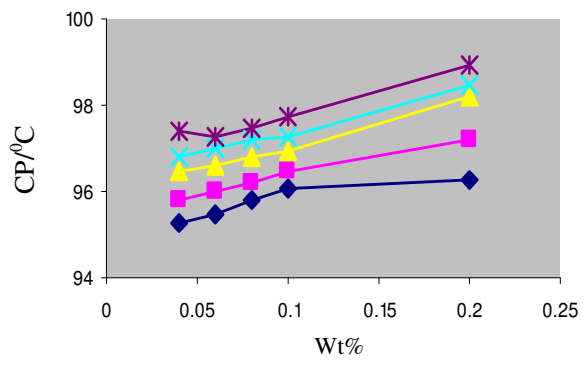

Figure 2. CP of Tween-40+CAT

\section{Thermodynamics of clouding}

All physicochemical processes are energetically controlled. The spontaneous formation of micelle is obviously guided by thermodynamic principles. The energetic of such processes are required for formulation, uses and basic understanding. Thermodynamic parameters of pure Tween-40 and Tween- $40+$ CAT mixed system are given in Table 2 and 4 respectively. In case of nonionic surfactant, the desolvation of hydrophilic groups of the surfactant leads to the formation of cloud or turbidity in the surfactant solution at elevated temperature. The appearance of cloud point is entropy dominated. At the cloud point, the water molecules get detached from the micelles. Considering cloud point as the phase separation point, the thermodynamic parameters such as standard free energy $\left(\Delta \mathrm{G}_{\mathrm{cl}}^{0}\right)$, enthalpy $\left(\Delta \mathrm{H}_{\mathrm{cl}}^{0}\right)$ and entropy $\left(\Delta \mathrm{S}_{\mathrm{cl}}^{0}\right)$ for the clouding process have been calculated using the Phase separation Model $^{15}$.

$$
\Delta \mathrm{G}_{\mathrm{cl}}^{0}=-\mathrm{RT} \ln \mathrm{Xs}
$$

Where "cl" stands for clouding process and $\ln \mathrm{Xs}$ is the mole fractional solubility of the solute. The Standard enthalpy $\left(\Delta \mathrm{H}_{\mathrm{cl}}^{0}\right)$ for the clouding process have been calculated from the slope of the linear plot of $\ln \mathrm{Xs} v s .1 / \mathrm{T}$ in Figure 1.

$$
\mathrm{d} \ln \mathrm{Xs} / \mathrm{dT}=\underset{0}{\Delta \mathrm{H}_{\mathrm{c} 1}^{0}} / \mathrm{RT}^{2}
$$

The Standard free energy $\left(\Delta \mathrm{S}_{\mathrm{cl}}\right)$ of the clouding process have been calculated from the following relationship

$$
\Delta \mathrm{S}_{\mathrm{cl}}^{0}=\left(\Delta \mathrm{H}_{\mathrm{cl}}^{0}-\Delta \mathrm{G}_{\mathrm{cl}}^{0}\right) / \mathrm{T}
$$


$\Delta \mathrm{H}_{\mathrm{cl}}^{0}<\Delta \mathrm{G}_{\mathrm{cl}}^{0}$ indicating that overall clouding process is exothermic and $\Delta \mathrm{H}_{\mathrm{cl}}^{0}>\mathrm{T} \Delta \mathrm{S}_{\mathrm{cl}}^{0}$ indicate that the process of clouding is guided by both enthalpy and entropy ${ }^{16}$. The present work would be supportive evidence regarding the probable interaction between non-ionic surfactant and macromolecules leading to the phase separation at the cloud point. The effect of CAT on the cloud point is a clear indication that the phenomenon of clouding is associated with the different micelles coalescing. This paper supports the conjecture that the cloud point is a critical phenomenon.

\section{Acknowledgment}

The author Mr. A. A. Patil is thankful to Dr. A. Z. Patil, Hon'ble Chairman, JET's Z.B.Patil College, Dhule, Hon'ble Principal, Z.B.Patil College, Dhule, Head, Department of Chemistry and all colleagues of Department of Chemistry, Z.B.Patil College, Dhule for their kind cooperation.

\section{References}

1. $\quad$ Miller J and Parker A J, J Am Chem Soc., 1961, 83, 117.

2. Ramabrahaman K and Suryanarayana M, Indian J Pure Appl Phys., 1968, 6, 422.

3. Ajith S and Rakshit A K, Langmuir, 1995, 11, 1122

4. Koshy L and Rakshit A K, Bull Chem Soc Jpn., 1991, 64, 2610.

5. McBain J W, Trans Farad Soc., 1913, 9, 99.

6. $\quad$ Almgren M and Swarup S, J Phy Chem., 1982, 86, 4212.

7. Bellare J R, Kaneko T and Evans D F, Langmuir, 1988, 4, 1066.

8. Myers D, Surfactant Science and Technology, $2^{\text {nd }}$ Ed., VCH, New York, 1963.

9. Shinoda K, Nakagawa T, Tamamushi B and Isemura T, Colloidal Surfactant, Some Physicochemical properties, Academic Press, New York, 1963.

10. Kjellander R and Florin E, J Chem Soc Faraday Trans I, 1981, 77, 2053-2077.

11. Blankschtein D, Thurston G M and Benedeck G B, J Chem Phy., 1986, 85(12), 7268-7288.

12. Rupert L A M, J Colloid Interface Sci., 1992, 153, 92.

13. Fogg P G T, J Chem Soc., 1958, 4111.

14. Bhadane B S and Patil T J, Orient J Chem., 2008, 24(3), 253-256.

15. Attwood D and Florence A T, Surfactant Systems Champman and Hall, London, 1983, 99.

16. Patil T J and Patil H A, Int J Chem Sci., 2005, 3(3), 507. 


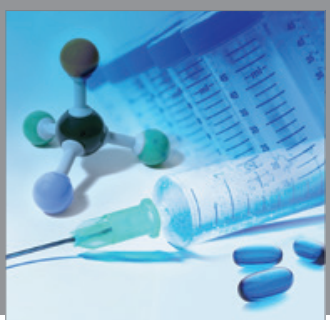

International Journal of

Medicinal Chemistry

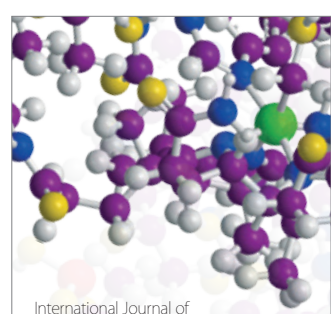

Carbohydrate Chemistry

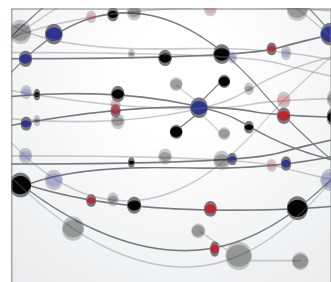

The Scientific World Journal
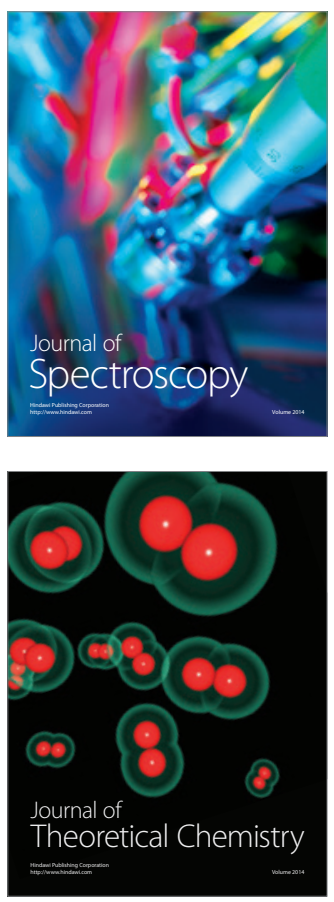
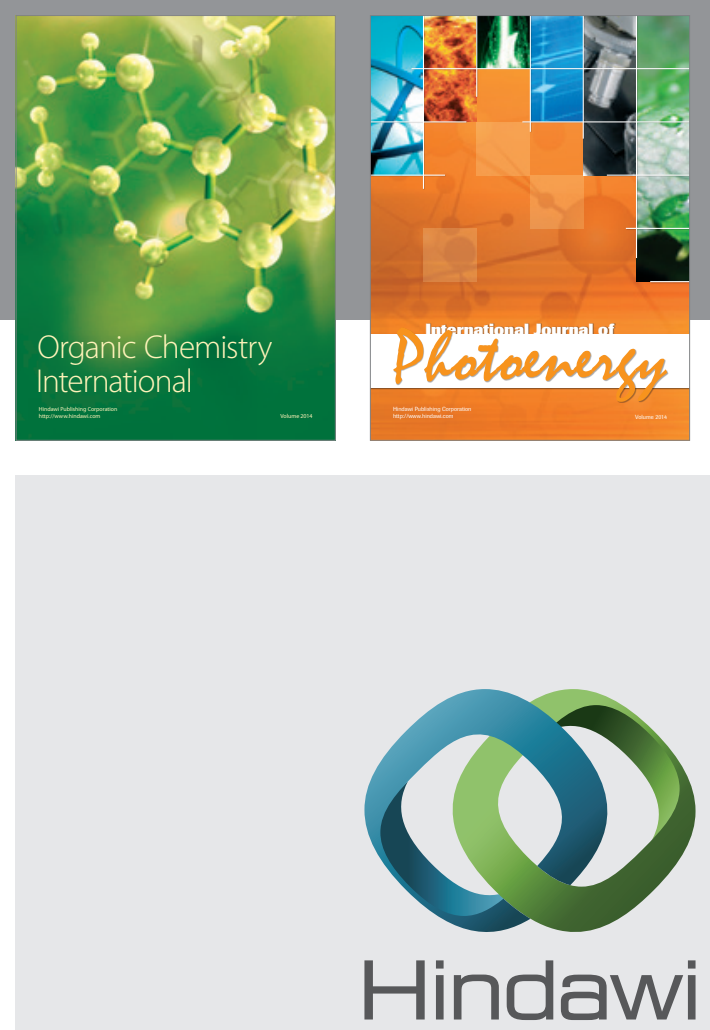

Submit your manuscripts at

http://www.hindawi.com
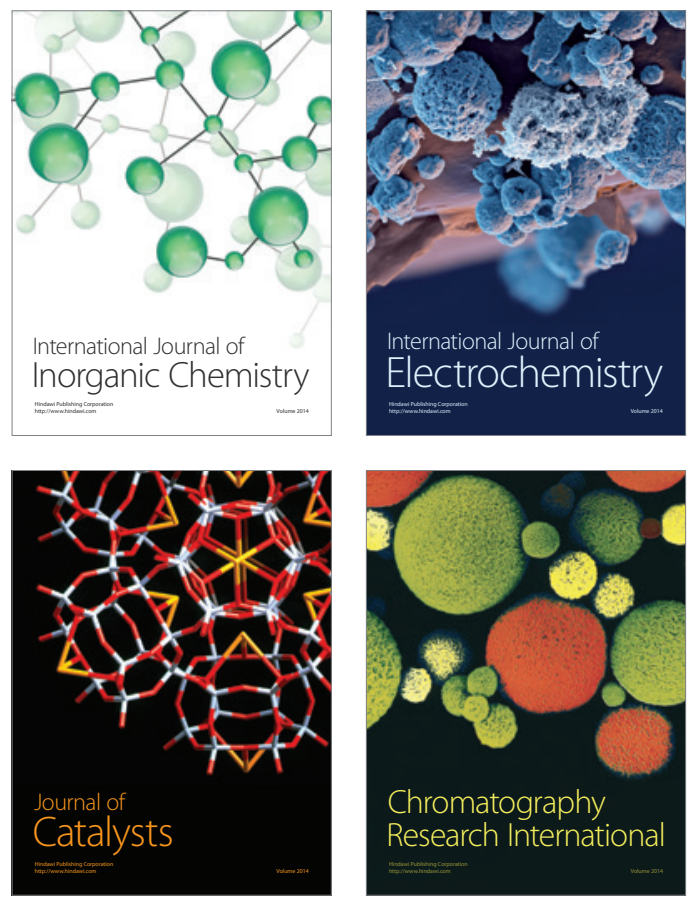
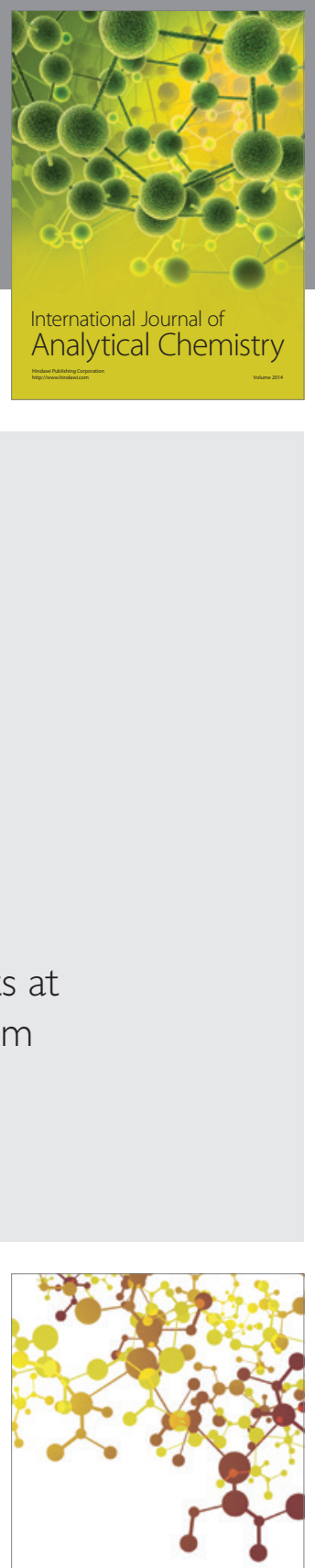

Journal of

Applied Chemistry
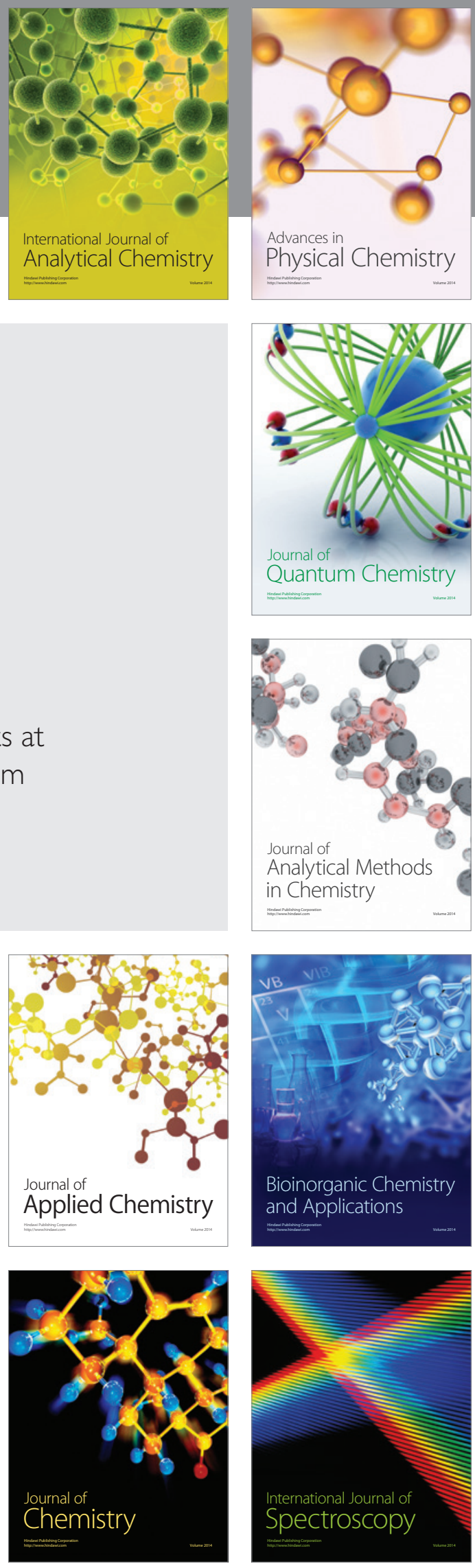